\title{
Article \\ Prediction of Arsenic Removal from Contaminated Water Using Artificial Neural Network Model
}

\author{
Mohammed Al-Yaari ${ }^{1, *(1)}$, Theyazn H. H. Aldhyani ${ }^{2}{ }^{(1)}$ and Sayeed Rushd ${ }^{1}$ \\ 1 Chemical Engineering Department, King Faisal University, P.O. Box 380, Al-Ahsa 31982, Saudi Arabia; \\ mrushd@kfu.edu.sa \\ 2 Applied College in Abqaiq, King Faisal University, P.O. Box 400, Al-Ahsa 31982, Saudi Arabia; \\ taldhyani@kfu.edu.sa \\ * Correspondence: malyaari@kfu.edu.sa; Tel.: +966-13-589-8583
}

check for updates

Citation: Al-Yaari, M.; Aldhyani, T.H.H.; Rushd, S. Prediction of Arsenic Removal from Contaminated Water Using Artificial Neural Network Model. Appl. Sci. 2022, 12, 999. https://doi.org/10.3390/ app12030999

Academic Editor: Raffaele Marotta

Received: 1 January 2022

Accepted: 17 January 2022

Published: 19 January 2022

Publisher's Note: MDPI stays neutral with regard to jurisdictional claims in published maps and institutional affiliations.

Copyright: () 2022 by the authors Licensee MDPI, Basel, Switzerland. This article is an open access article distributed under the terms and conditions of the Creative Commons Attribution (CC BY) license (https:// creativecommons.org/licenses/by/ $4.0 /)$.

\begin{abstract}
Arsenic is a deleterious heavy metal that is usually removed from polluted water based on adsorption processes. The latest mode of modeling such a process is to implement artificial intelligence (AI). In the current work, a new artificial neural network (ANN) model was developed to predict the adsorption efficiency of arsenate $(A s(\mathrm{III}))$ from contaminated water by analyzing different architectures of an adaptive network-based fuzzy inference system (ANFIS). The database for the current study consisted of the experimental data of the adsorption of $A s$ (III) by different adsorbents/biosorbents. The data were randomly divided into two sets: $70 \%$ for the training phase and 30\% for the testing phase. Four statistical evaluation metrics, namely, mean square error (MSE), root-mean-square error (RMSE), Pearson's correlation coefficient (R\%), and the determination coefficient $\left(\mathrm{R}^{2}\right)$ were used for the analysis. The best performing ANFIS model was characterized with the average values of $97.72 \%, 0.9333,0.137$, and 0.274 of $\mathrm{R} \%, \mathrm{R}^{2}, \mathrm{MSE}$, and RMSE, respectively. In addition, a parametric investigation revealed that the most dominating parameters on the adsorption process efficiency were in the following order: $\mathrm{pH}$, As initial concentration, contact time, adsorbent dosage, inoculum size, and temperature. The results of the current study would be useful in the adsorption process scale-up and optimization.
\end{abstract}

Keywords: heavy metals; arsenic; adsorption; artificial neural network (ANN); adaptive networkbased fuzzy inference system (ANFIS)

\section{Introduction}

Heavy metals, discharged even at low concentrations into natural water bodies, have threatening impacts on human life and the environment. One of such toxic heavy metals is arsenic $(A s)$, which is considered an environmental hazard [1]. The immediate symptoms of acute $A s$ poisoning include abdominal pain and vomiting. It can lead to death in extreme cases. Long-term exposure can cause diabetes, pulmonary disease, cardiovascular disease, cancer, and skin lesions [2]. Various technologies, such as coagulation-filtration [3], membrane separation [4,5], ion exchange [6], adsorption $[7,8]$, and hybrid membrane systems $[9,10]$ have been employed to remove As from contaminated water. Among these methods, adsorption is probably the most effective separation method for the removal of hazardous heavy metals such as $A$ s from water. The adsorption process has long been used in the water and wastewater industries for its ease of handling, minimal sludge production, cost-effectiveness, and regeneration capability [11].

An integral part of the application of an adsorbent in removing a heavy metal ion from a contaminated aqueous solution is developing a process model. The traditional means of modeling adsorption is to obtain the parameters of the kinetic and isotherm models using experimental data at optimum conditions. However, the optimum values of the adsorption variables, such as $\mathrm{pH}$, adsorbent dosage, adsorbate initial concentration, contact time, and 
temperature, are investigated independently [7,12-14]. Considering the analytical error, uncertainty, and independent investigation associated with the traditional experimental work, different artificial intelligence (AI)-based machine learning (ML) models are being used to correlate all input variables to the output parameter (contaminant removal percentage) directly. A few examples of such applications are presented in Table 1.

Table 1. Examples of machine learning algorithms used to model adsorption processes.

\begin{tabular}{cccc}
\hline Heavy Metal & Adsorbent & Model & Reference \\
\hline Copper & Biochar & ANN & ANN \\
\hline Arsenic & A hybrid material & Mandal et al. (2015) [15] & ANN \\
\hline Arsenic & Botryococcus braunii algal biomass & ANN and \\
\hline $\begin{array}{c}\text { Arsenic } \\
\text { arsenic, copper, zinc }\end{array}$ & Cupric oxide nanoparticles & genetic algorithm \\
\hline
\end{tabular}

Superheated steam-activated granular carbon, ragi husk powder,

antep pistachio, pistacia vera, red mud, synthesized functional polydopamine

Lead, arsenic, nanocomposite, eucalyptus leaves, chromium, cadmium, mercury

spirulina maxima, spirulina indica, spirulina platensis, reduced graphene oxide-supported nanoscale zero-valent iron composites,

cupric oxide nanoparticles, and cerium hydroxylamine hydrochloride

Hybrid material, Botryococcusbrauni algal biomass, microalgae $C$.

Arsenic pyrenoidosa, cupric oxide nanoparticles, Oyster shell, Palm bark biomass, and Bacillus cereus biomass

\begin{tabular}{|c|c|c|c|}
\hline Copper & Attapulgite clay & $\begin{array}{l}\text { ANN, support vector } \\
\text { machine, and random forest }\end{array}$ & Bhagat et al. (2021) [22] \\
\hline Lead, copper, nickel & Date seed-derived biochar & ANN & El Hanandeh et al. (2021) [23] \\
\hline $\begin{array}{l}\text { Lead, cadmium, nickel, } \\
\text { arsenic, copper, zinc }\end{array}$ & Biochar & ANN & Ke et al. (2021) [24] \\
\hline Chromium & Clay & ANFIS & Foroutan et al. (2020) [25] \\
\hline Copper & Saw dust & ANFIS & Dolatabadi et al. (2018) [26] \\
\hline Copper & Biochar & ANFIS & Wong et al. (2020) [27] \\
\hline
\end{tabular}

The mostly used ML algorithm for modeling various adsorption processes is the artificial neural network (ANN) [28,29]. It has been used all across the world for classification and prediction purposes in a wide range of real-time adsorption applications [14-18,22-27]. The ANN correlates the input(s) to the output(s) with nodes arranged in single or multiple hidden layers. The nodes in one layer are connected with weight functions to the nodes in the next layer. An activation function is used to non-linearly map the inputs to the outputs.

In addition to ANN, other machine learning algorithms (MLAs) such as decision trees, support vector regression, random forest, genetic model, particle swarm optimization, and adaptive network-based fuzzy inference system (ANFIS) have been used for modeling various adsorption processes [18-22,25-27]. Among these MLAs, the ANFIS has the advantages of the ability to capture the non-linear structure of a process, adaptation 
capability, and rapid learning capacity. It is a sub-category of ANN that integrates the principles of neural networks and fuzzy logic to acquire the advantages of both in a single computational platform. Compared to other MLAs, ANFIS has not been used to model the adsorption of As. Although it was applied earlier for modeling the adsorption of other heavy metals, such as copper and chromium [25-27], those models are based on a single dataset with a relatively high prediction error. Therefore, a generalized model, using different datasets with different adsorbents, needs to be developed.

In this work, a highly efficient ANFIS model was developed to predict the adsorption removal efficiency of arsenate $(A s(\mathrm{III}))$ from aqueous solutions. A parametric investigation was also performed to identify the contribution of the input parameters in predicting the output parameter (As removal \%).

\section{Materials and Methods}

\subsection{Database}

Seven experimental datasets were selected from the literature [15-18,30-32] for the current study. These studies were considered suitable, as a variety of absorbents or biosorbents were used to remove $A s$ (III) from contaminated aqueous solutions or ground/wastewater. In general, the adsorption or biosorption experimentation was followed by modeling $A s$ removal based on several input parameters, including initial $A$ s concentration, adsorbent dose, $\mathrm{pH}$, contact time, agitation speed, temperature, and others.

\subsection{ANFIS Model}

The ANFIS model was introduced as a combination of the neural network model and fuzzy logic [33-38]. The ANFIS model showed a better performance in processing a small size of training datasets when compared to ANN [39]. A typical architecture of the ANFIS model has five layers: fuzzification, rule, normalization, defuzzification, and aggregation [40-43]. In this study, the Takagi-Sugeno function and if-then rules were used to represent the non-linear relationship between the input and the output parameters $[44,45]$.

A fuzzy inference system with two inputs and one output is used in describing the ANFIS model. The rules of the fuzzy inference system are shown as follows:

$$
\begin{aligned}
& \text { Rule } 1 \text { : if } x \text { is } A_{1} \text { and } y \text { is } B_{1} \text {, then } f_{1}=p_{1} x+q_{1} y+r_{1} \\
& \text { Rule } 1 \text { : if } x \text { is } A_{2} \text { and } y \text { is } B_{2} \text {, then } f_{1}=p_{2} x+q_{2} y+r_{2}
\end{aligned}
$$

where:

$A_{1}, A_{2}, B_{1}$, and $B_{2}$ are the fuzzy sets;

$x$, and $y$ are the input variables;

$p_{1}, p_{2}, q_{1}, q_{2}, r_{1}$, and $r_{2}$ : are the linear polynomial parameters; and

$f$ is the output of the ANFIS model.

The layers of the ANFIS model used for the current study are described below and illustrated in Figure 1.

Layer 1: This layer is called the fuzzification layer. In this layer, the fuzzy inference system uses a membership function to convert the input parameters into a fuzzy set. Among different types of membership functions, the Gaussian-shape membership function was applied in this work to map the training values between $[0,1]$.

$$
\mathrm{O}_{1, i}=\mu A_{i}\left(x_{i}\right)
$$

for $i=1,2$

$$
O_{1, i}=\mu B_{i}\left(y_{i}\right)
$$

for $i=1,2$

$$
\mu A_{i}\left(x_{i}\right)=\frac{1}{1+\left(\frac{x_{i}-c_{i}}{\sigma_{i}}\right)^{2 b_{i}}}
$$


where:

$\mathrm{O}_{1, i}$ is the output of layer 1 ;

$\mu$ is the Gaussian-shape membership function;

$A_{i}$, and $B_{i}$ represent the linguistic variables;

$x$ and $y$ are the input variables; and

$\sigma_{i}, b_{i}$, and $c_{i}$ are the constants of the Gaussian-shape function.

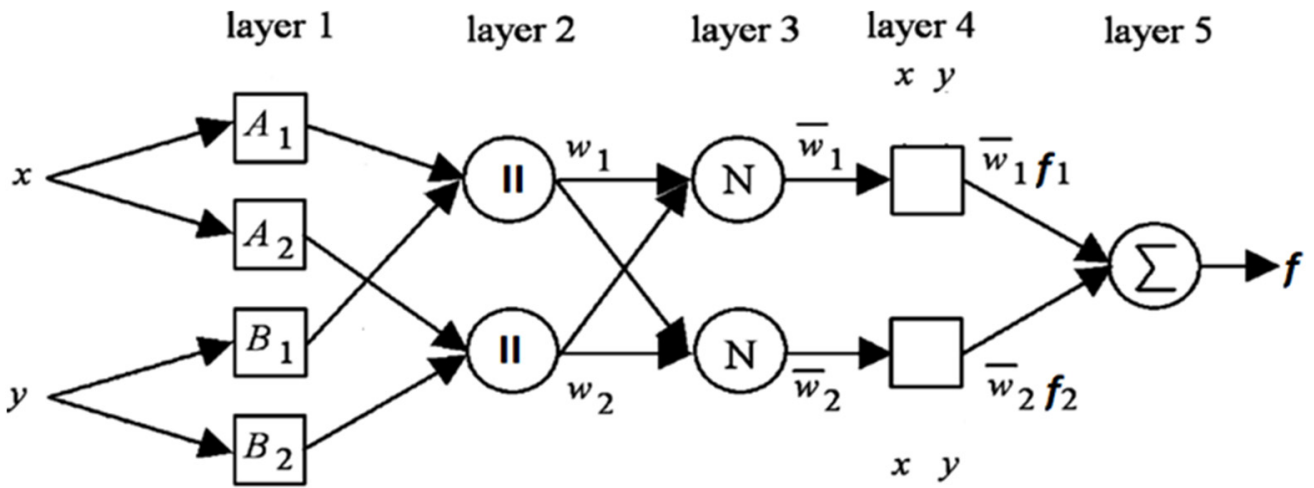

Figure 1. The architecture of the ANFIS model with two rules.

Layer 2: This layer has fixed nodes. The output of this layer is attained by multiplying all the receiving signals from the input layer. The output is represented by $w_{i}$

$$
O_{2, i}=w_{i}=\mu A_{i}(x) * \mu B_{i}(y), i=1,2 .
$$

Layer 3: The nodes in this layer are fixed and labeled as $N$. In this layer, the outputs are obtained using the firing strength inference system rules.

$$
\mathrm{O}_{3, i}=\bar{w}_{i}=\frac{w_{i}}{w_{1+w_{2}}}, i=1,2
$$

where:

$\mathrm{O}_{3, i}$ is the output of layer 3; and

$\bar{w}$ is the normalized firing strength of the inference system rules.

Layer 4: This layer has adaptive nodes. It has three parameters used to adjust the adaptive nodes.

$$
O_{4, i}=\bar{w}_{i} \cdot f_{i}=\bar{w}_{i} \cdot\left(p_{i} x+q_{i} y+r_{i}\right)
$$

where:

$\mathrm{O}_{4, i}$ is the output of layer 4 ; and

$p_{i}, q_{i}$, and $r_{i}$ are the parameters of the inference system.

Layer 5: This layer is the inference layer, which is used to obtain the overall output based on the previous layers.

$$
O_{5, i} \text { overall output }=\sum \bar{w}_{i} f_{i}=\frac{\sum_{i} \bar{w}_{i} f_{i}}{\sum_{i} w_{i}}
$$

Earlier, the ANFIS model demonstrated a good performance in predicting the removal efficiency of some heavy metals other than As from aqueous solutions [25-27].

\subsection{Performance Evaluation}

A set of statistical analysis metrics comprised of mean square error (MSE), rootmean-square error $(R M S E)$, Pearson's correlation coefficient $(R \%)$, and the determination 
coefficient $\left(R^{2}\right)$ were used to evaluate the developed ANFIS model in this study. All of these statistical parameters are defined as follows:

$$
\begin{gathered}
M S E=\frac{1}{n} \sum_{i=1}^{n}\left(y_{i, \exp }-y_{i, \text { pred }}\right)^{2} \\
R M S E=\sqrt{\sum_{i=1}^{n} \frac{\left(y_{i, \exp }-y_{i, \text { pred }}\right)^{2}}{n}} \\
R \%=\frac{n\left(\sum_{i=1}^{n} y_{i, \exp } \times y_{i, \text { pred }}\right)-\left(\sum_{i=1}^{n} y_{i, \exp }\right)\left(\sum_{i=1}^{n} y_{i, \text { pred }}\right)}{\sqrt{\left[n\left(\sum_{i=1}^{n} y_{i, \exp }\right)^{2}-\left(\sum_{i=1}^{n} y_{i, \exp }\right)^{2}\right]\left[n\left(\sum_{i=1}^{n} y_{i, \text { pred }}\right)^{2}-\left(\sum_{i=1}^{n} y_{i, \text { pred }}\right)^{2}\right]}} \times 100 \\
R^{2}=1-\frac{\sum_{i=1}^{n}\left(y_{i, \exp }-y_{i, \text { pred }}\right)^{2}}{\sum_{i=1}^{n}\left(y_{i, \exp }-y_{\text {avg }, \exp }\right)^{2}}
\end{gathered}
$$

where:

$y_{i, e x p}$ is the experimental value of the data point $i$;

$y_{i, \text { pred }}$ is the predicted value of the data point $i$;

$y_{\text {avg,exp }}$ is the average of the experimental values; and

$n$ is the total number of the input data.

\subsection{Parametric Importance Analysis}

After developing an AI model, it is necessary to conduct a parametric importance analysis. It allows identifying the most dominating parameters and checking if any input parameter can be omitted to simplify the model. In this work, an importance investigation of each parameter was performed for each dataset. Multiple non-linear regressions were used to obtain the relationship between input and output parameters. The value of the Pearson's correlation coefficient ( $\mathrm{R} \%$ ) was used to evaluate the relative impact of each input parameter on the output parameter ( $A s$ removal percentage).

\section{Results and Discussion}

As mentioned earlier, an efficient ANFIS model was developed based on a database comprised of the experimental measurements published in seven independent studies. The computational platform used for the modeling was MATLAB 2020. The input variables used for the modeling were $A s$ initial concentration, $\mathrm{pH}$, temperature, contact time, adsorbent dosage, solution volume, agitation speed, inoculum size, and flow rate. The removal percentage of arsenate from the contaminated water was the output parameter. The log method was used for normalizing the data. The prediction capability of the developed model was evaluated using four statistical parameters: MSE, RMSE, R\%, and $\mathrm{R}^{2}$.

\subsection{Development of the ANFIS Model}

In this work, the scatter partition method was applied because of the small sizes of some experimental datasets. It depends on fuzzy clustering of the data subgroups to find the optimum membership values. The architecture of the ANFIS model is presented in Figure 2, while the values of the corresponding model parameters are mentioned in Table 2. 


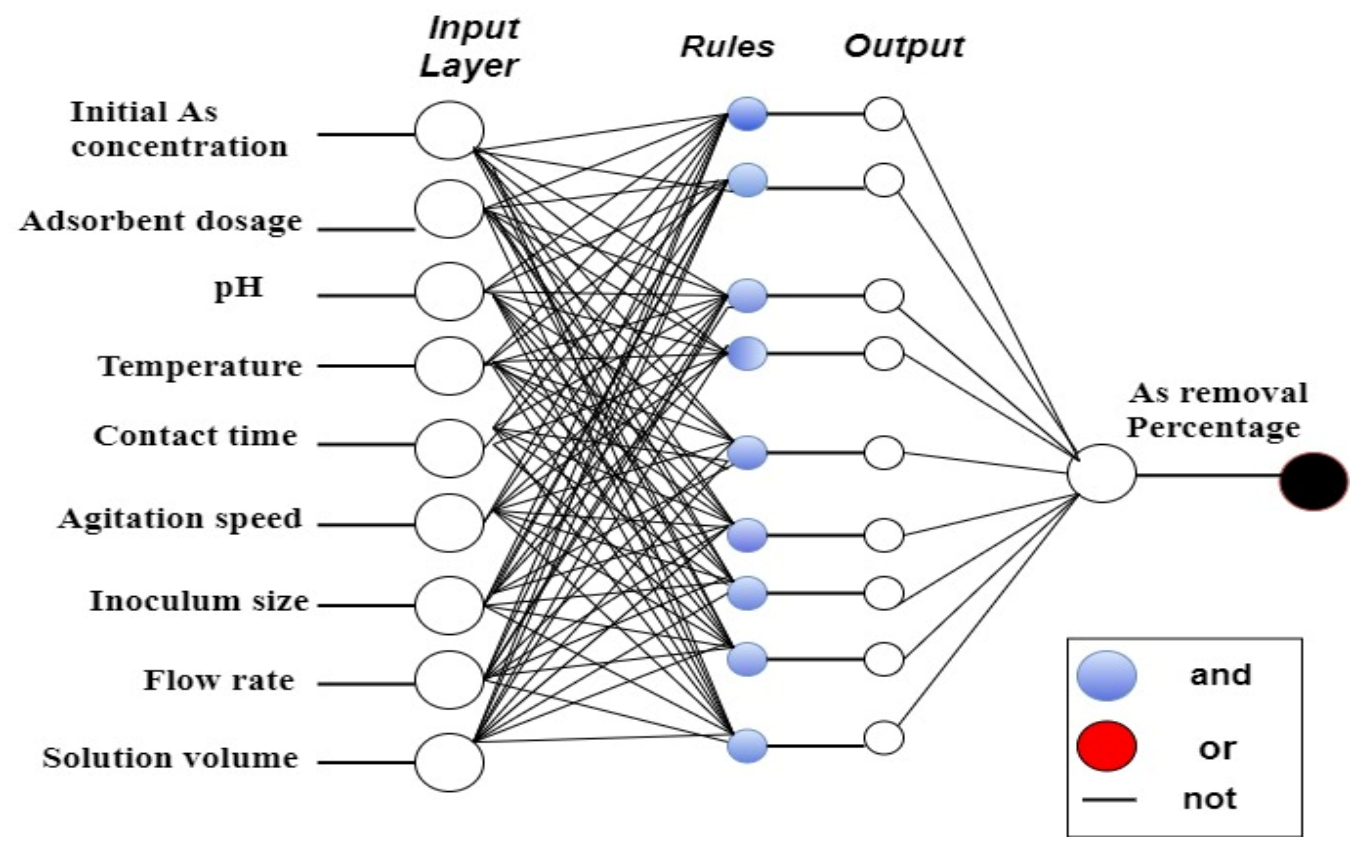

Figure 2. The topology of the ANFIS model.

Table 2. Parameters of the developed ANFIS model.

\begin{tabular}{cc}
\hline Parameter & Value \\
\hline Parameter cluster & 4 \\
Partition matrix & 2 \\
Maximum number of iterations & 200 \\
Minimum improvement & $1 \times 10^{-5}$ \\
Maximum number of epochs & 80 \\
Error goat & 0 \\
Initial steps size & 0.01 \\
Step size decrease rate & 0.9 \\
Step size increase rate & 1.1 \\
\hline
\end{tabular}

\subsection{Training Phase of the ANFIS Model}

The training process is an essential stage to develop an efficient model using experimental data. For this purpose, $70 \%$ of the data were used to train the developed ANFIS model. As mentioned earlier, the ANFIS model is based on fuzzy if-then rules and fuzzy reasoning. Therefore, the results of the ANFIS model have no deviation, and this is one of the advantages of this model.

The performance of the developed ANFIS model is shown in Figure 3, and the values of the evaluation metrics are presented in Table 3. The training results show the full agreement between the predicted values and experimental measurements of the arsenate removal percentage for all datasets. High values of $R \%(\geq 99.99 \%)$ or $R^{2}(\geq 0.9995)$ and very low values of MSE or RMSE indicate that the ANFIS model is ready to be tested.

\subsection{Testing of the ANFIS Model}

Thirty percent (30\%) of the data were used as the unseen data to test and validate the current ANFIS model. Its performance in the testing stage is illustrated in Figure 4 and Table 4. As shown in Figure 4, an excellent agreement between the predicted values and the targeted (experimental) values could be achieved. Similar to the training phase, high values of $\mathrm{R} \%(97.72 \%)$ or $\mathrm{R}^{2}$ (0.9333) and low values of MSE (0.137) or RMSE (0.274) were attained. This kind of agreement indicates the robustness of the developed ANFIS model in predicting the As removal from polluted water by the adsorption processes. 


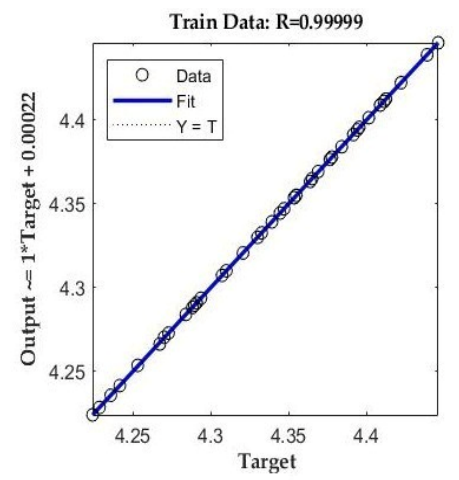

(a)

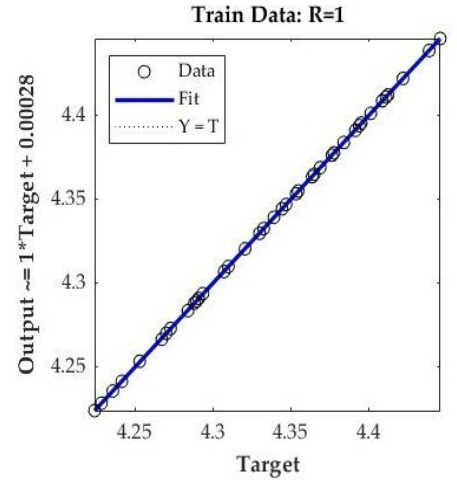

(b)

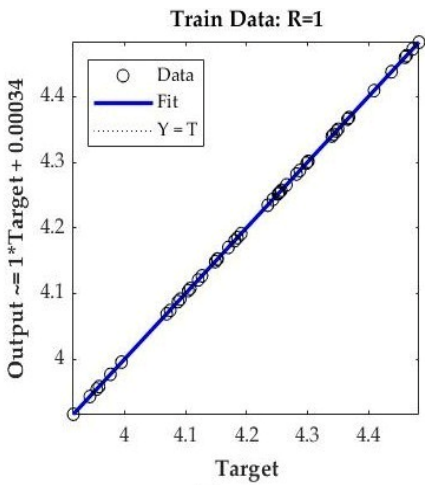

(c)

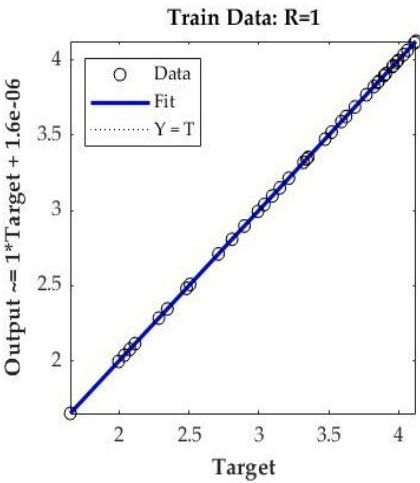

(d)

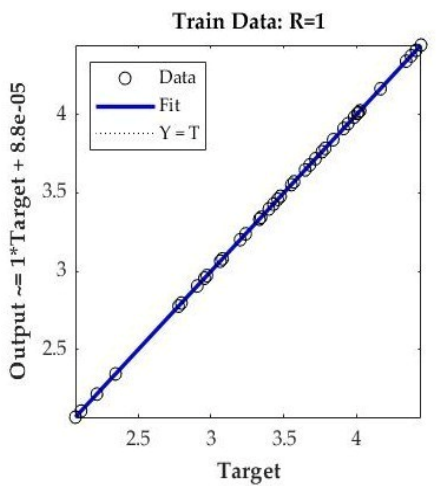

(e)

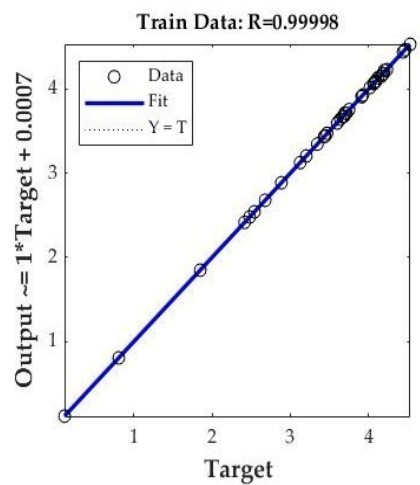

(f)

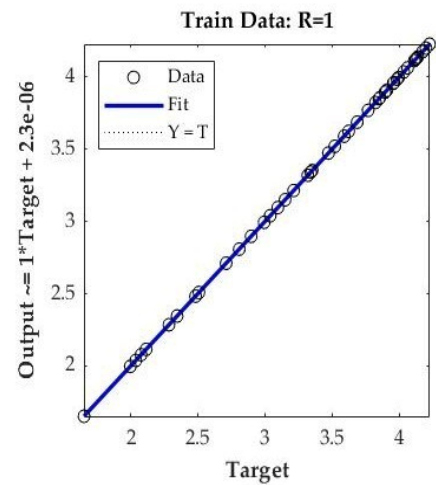

(g)

Figure 3. Performance of the ANFIS model in the training phase: (a) dataset 1, (b) dataset 2, (c) dataset 3, (d) dataset 4, (e) dataset 5, (f) dataset 6, and (g) dataset 7 .

Table 3. Performance of the ANFIS model in the training stage.

\begin{tabular}{ccccc}
\hline Dataset & MSE & RMSE & R (\%) & $\mathbf{R}^{\mathbf{2}}$ \\
\hline 1 & $1.7447 \times 10^{-8}$ & $1.320 \times 10^{-4}$ & 100 & 1 \\
2 & $8.84436 \times 10^{-8}$ & $1 \times 10^{-4}$ & 100 & 0.9997 \\
3 & $4.0718 \times 10^{-10}$ & $2.0179 \times 10^{-5}$ & 100 & 0.9996 \\
4 & $1.6415 \times 10^{-8}$ & $1.28 \times 10^{-3}$ & 100 & 0.9995 \\
5 & $3.2906 \times 10^{-5}$ & $5.76 \times 10^{-3}$ & 99.99 & 0.9998 \\
6 & $3.3013 \times 10^{-8}$ & $1.8 \times 10^{-4}$ & 100 & 0.9998 \\
7 & $4.5042 \times 10^{-8}$ & $2.123 \times 10^{-3}$ & 99.99 & 0.9999 \\
\hline
\end{tabular}

Even though ANFIS was used to model the adsorption of other heavy metals such as chromium and copper [25-27], it was not applied earlier to model As adsorption. Its application to model $A s$ adsorption is a novel contribution of the current study. A comparative performance of different MLAs is presented in Table 5. The MLAs used before to model $A s$ adsorption were ANN, random forest (RF), and support vector regression (SVR) [15-19]. The primary challenge the researchers faced to use ANN was the small sizes of the datasets [15-18]. They overcame the challenge by producing synthetic data using a specific algorithm for interpolation. However, they did not use any means to validate the utility of this kind of artificial data. On the other hand, Hafsa et al. [21] tested two non-ANN models, RF and SVR, for modeling As adsorption. Even though these MLAs could predict the trends quite well $\left(R^{2}>0.93\right)$, the errors or data dispersions were significantly high (RMSE > 2.5). In comparison, the current ANFIS model not only could predict the trends of the data more accurately $\left(R^{2}>0.93\right)$ but also yielded significantly less error (RMSE $<0.48$ ). It should be noted that Hafsa et al. [21] used the same datasets as those used for the current study. 


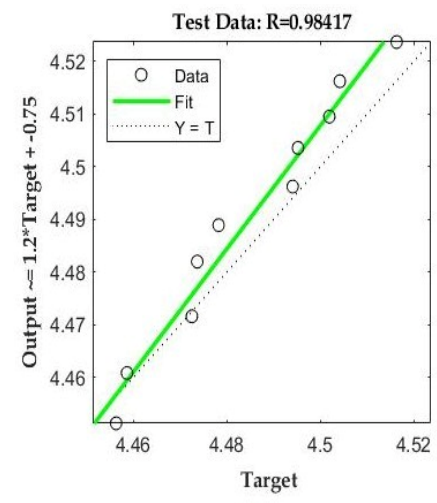

(a)

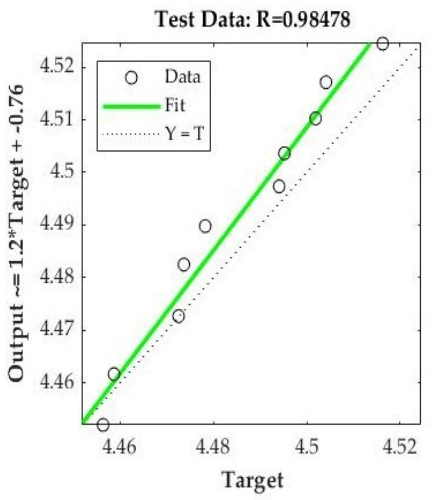

(b)

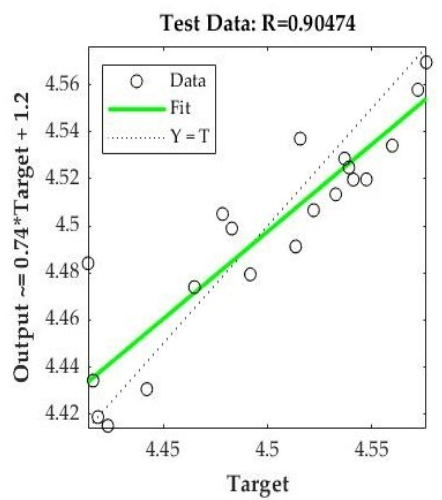

(c)

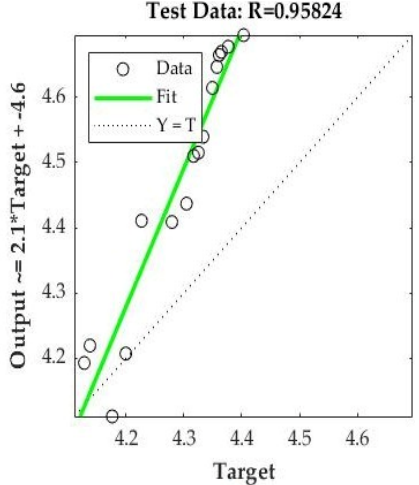

(d)

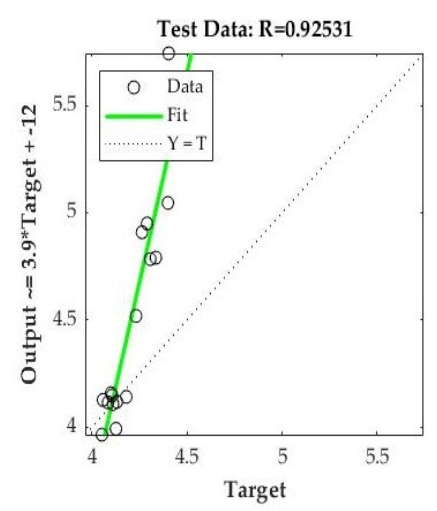

(e)

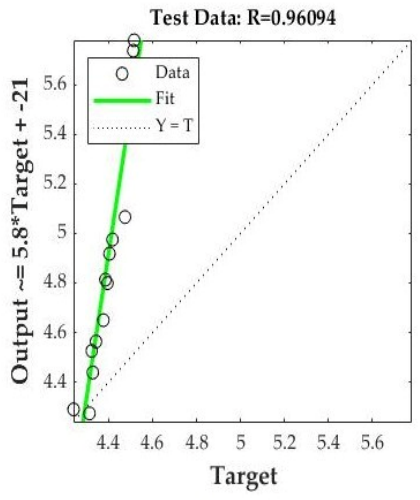

(f)

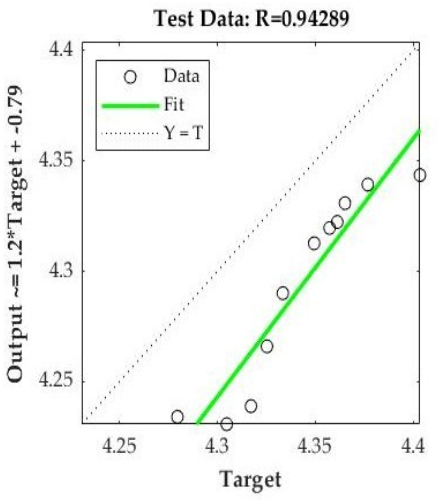

(g)

Figure 4. Performance of the ANFIS model in the testing phase: (a) dataset 1, (b) dataset 2, (c) dataset 3 , (d) dataset 4 , (e) dataset $5,($ f) dataset 6 , and (g) dataset 7.

Table 4. Testing results of the ANFIS model.

\begin{tabular}{ccccc}
\hline Dataset & MSE & RMSE & R (\%) & $\mathbf{R}^{\mathbf{2}}$ \\
\hline 1 & $8.96 \times 10^{-4}$ & $2.994 \times 10^{-2}$ & 99.16 & 0.9580 \\
2 & 0.2260 & 0.4754 & 92.53 & 0.9423 \\
3 & $4.4564 \times 10^{-2}$ & 0.2111 & 95.82 & 0.9054 \\
4 & $2.69 \times 10^{-3}$ & $5.186 \times 10^{-2}$ & 99.97 & 0.9226 \\
5 & 0.4770 & 0.6907 & 96.69 & 0.9114 \\
6 & 0.207 & 0.4549 & 99.94 & 0.9490 \\
7 & $5.4221 \times 10^{-5}$ & $7.36 \times 10^{-3}$ & 99.94 & 0.9443 \\
\hline Average & $\mathbf{0 . 1 3 7}$ & $\mathbf{0 . 2 7 4}$ & $\mathbf{9 7 . 7 2}$ & $\mathbf{0 . 9 3 3 3}$ \\
\hline
\end{tabular}

\subsection{Parametric Importance Analysis}

The impact of nine parameters on the As removal percentage was investigated in this study. However, all experimental parameters are not expected to have similar impacts on predicting the output. Therefore, the relative importance of each parameter in each dataset was quantified using the values of $\mathrm{R} \%$. The higher the $\mathrm{R} \%$ value, the higher the importance of the parameter. Among all the investigated parameters, $\mathrm{pH}$, the As initial concentration, and contact time were found as the most influential parameters with different impacts. While $\mathrm{pH}$ scored the highest of 575, the initial concentration and contact time scored 568 and 445 , respectively. Figure 5 shows the importance of each input parameter on the efficiency of As adsorption for all datasets. The current investigation provides a comparative ranking of the most dominating parameters in modeling the arsenic adsorption process: $\mathrm{pH}>$ arsenate initial concentration $>$ contact time $>$ adsorbent mass $>$ inoculum size $>$ temperature. 
Table 5. Comparative performance of different MLAs in predicting the adsorption of heavy metals.

\begin{tabular}{|c|c|c|c|}
\hline Heavy Metal & Model & Evaluation Metrics & Reference \\
\hline Chromium & ANFIS & $\begin{array}{c}\mathrm{R}^{2}=0.9997 \\
\mathrm{MSE}=1.288 \times 10^{-06}\end{array}$ & Foroutan et al. (2020) [25] \\
\hline Copper & ANFIS & $\begin{array}{c}\mathrm{R}^{2}=0.99 \\
\mathrm{MSE}=0.707\end{array}$ & Dolatabadi et al. (2018) [26] \\
\hline Copper & ANFIS & $\begin{array}{l}\mathrm{R}^{2}=0.9024 \\
\mathrm{MSE}=3.29\end{array}$ & Wong et al. (2020) [27] \\
\hline Arsenic & ANN & $\begin{array}{c}\mathrm{R}^{2}=0.9975 \\
\text { Relative } \% \text { error }=0.293\end{array}$ & Mandal et al. (2015) [15] \\
\hline Arsenic & ANN & $R^{2}=0.9998$ & Podder et al. (2016) [16] \\
\hline Arsenic & ANN & $R^{2}=0.9987$ & Podder et al. (2017) [17] \\
\hline Arsenic & ANN-GA & $\begin{array}{c}\mathrm{R}^{2}=0.9984 \\
\mathrm{MSE}=0.036 \\
\% \text { Error }(\mathrm{abs})=3.16\end{array}$ & Singh et al. (2017) [18] \\
\hline Arsenic & RF, and SVR & $\begin{array}{c}\text { RF: } \\
\mathrm{R}^{2}=0.954 \\
\text { RMSE }=2.8 \\
\text { MAE }=0.96 \\
\text { SVR: } \\
\mathrm{R}^{2}=0.939 \\
\text { RMSE }=2.9 \\
\text { MAE }=1.9\end{array}$ & Hafsa et al. (2021) [21] \\
\hline Arsenic & ANFIS & $\begin{array}{c}\mathrm{R}^{2}=0.933 \\
\mathrm{MSE}=0.137 \\
\mathrm{RMSE}=0.274\end{array}$ & Current Study \\
\hline
\end{tabular}

Generally, as the $\mathrm{pH}$ increases, the concentration of $\mathrm{H}^{+}$ions decreases. The solution $\mathrm{H}^{+}$ ions can compete for the available total active sites, thus reducing the active sites available for the As ions. Therefore, increasing $\mathrm{pH}$ can increase the removal percentage of $A s$ [46]. However, there is an optimum value beyond which any further increase in $\mathrm{pH}$ will not affect the adsorption efficiency. Therefore, the value of $\mathrm{pH}$ must be optimized before conducting the batch adsorption experiments.

In addition, the arsenate removal percentage can be calculated using Equation (14). For the same adsorbent dosage (mass), as the adsorbate initial concentration increases, the removal percentage decreases [46]. An adsorbent has a limited number of active adsorption sites at which $A s$ ions are adsorbed. Therefore, insufficient active sites will be the case as the As concentration increases. Therefore, the initial concentration has a significant impact on the adsorption process.

$$
\text { Arsenic removal }(\%)=\frac{\left(C_{o}-C_{f}\right)}{C_{o}} \times 100
$$

where:

$C_{o}$ is the As initial concentration $(\mathrm{mg} / \mathrm{L})$; and

$C_{f}$ is the As concentration at the end of the experiment $(\mathrm{mg} / \mathrm{L})$.

Moreover, contact time is one of the dominating parameters in the adsorption process. As the contact time increases, the adsorption efficiency increases until reaching equilibrium, at which no further mass transfer will occur. The optimum contact time must be determined before conducting experiments. 

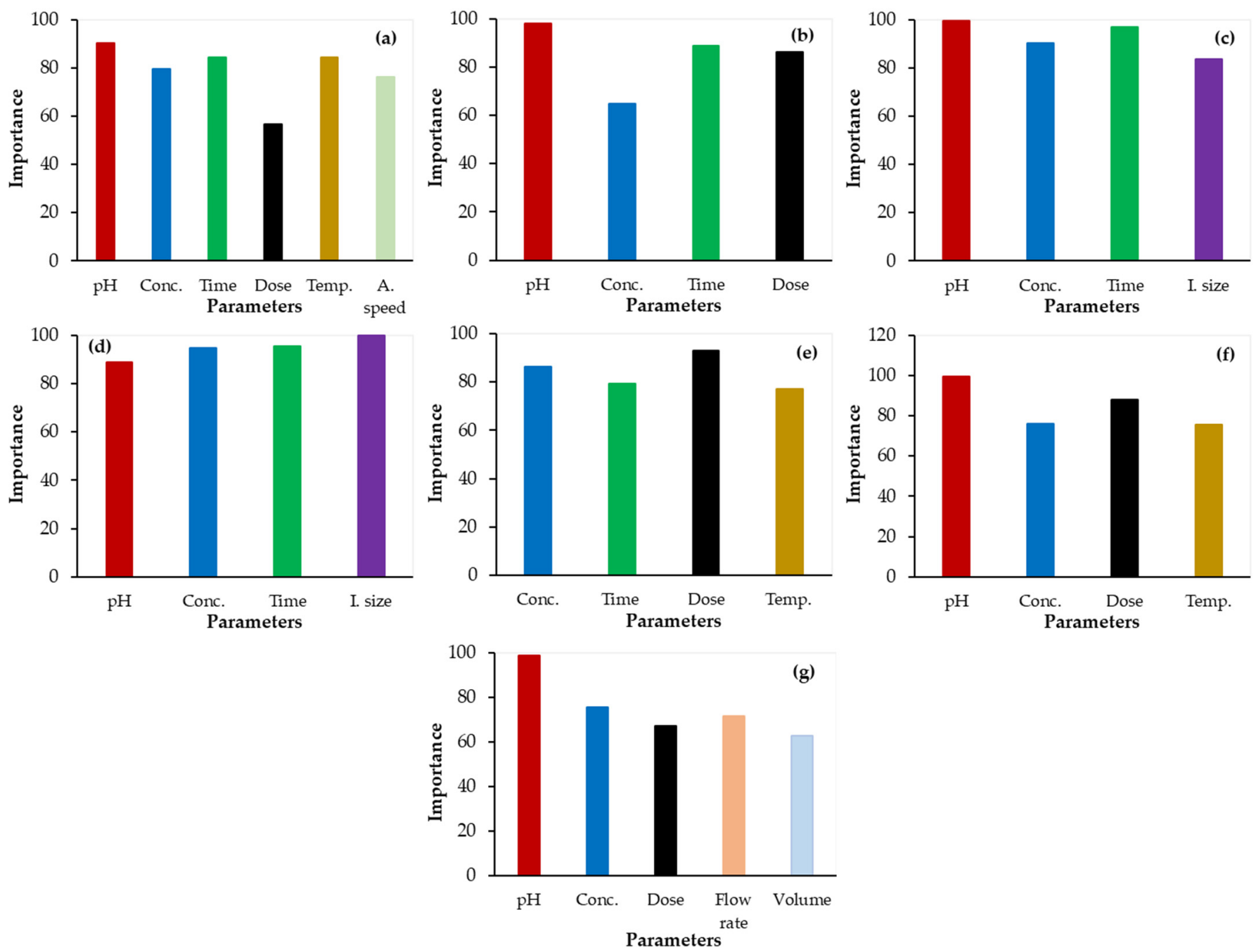

Figure 5. Importance of the experimental parameters on the adsorption efficiency: (a) dataset 1, (b) dataset 2, (c) dataset 3, (d) dataset 4, (e) dataset 5, (f) dataset 6, and (g) dataset 7.

Adsorbent dosage ranked fourth in terms of relative importance with a total score of 305. As the adsorbent dosage increases, the mass transfer surface area also increases for the same particle size. It enhances the adsorption efficiency. However, economic adsorbent mass, i.e., minimum mass with the highest adsorbability, should be used to achieve the optimum adsorption. Similarly, when using biosorbents, as the inoculum size increases, the adsorption efficiency increases. Therefore, the inoculum size ranked fifth in terms of relative importance with a total score of 270.

Furthermore, the nature and the spontaneity of the adsorption process have a significant effect on the removal efficiency. Temperature plays a key role in the determination of the thermodynamic properties of the adsorption process and thus has a non-negligible impact. Temperature ranked sixth in terms of relative importance with a total score of 237.

The rest of the parameters, namely, agitation speed, flow rate, and solution volume showed less significant impacts on the As removal efficiency. Their evaluation score varied between 63 and 76. That is, all the parameters selected for the current study had varying contributions in predicting the output. 


\section{Conclusions}

In this work, the application of the ANFIS model was investigated to predict the arsenate removal efficiency from aqueous solutions using different adsorbents at different conditions. Based on the promising results of this study, the following conclusions can be drawn:

- An efficient ANFIS model was successfully developed to predict the adsorption removal of arsenate from water. High values of $\mathrm{R} \%$ and $\mathrm{R}^{2}$ with low values of MSE/RMSE were reported for both training and testing phases.

- The parametric investigation of the current study can be used to optimize the parameters and, hence, increase the removal efficiency. The relative ranking of the most dominating parameters, in the modeling of the arsenate adsorption process, were as follows: $\mathrm{pH}$, arsenic initial concentration, contact time, adsorbent mass, inoculum size, and then temperature.

- Prediction of the removal of single or multi-component heavy metal/s can be investigated using an appropriate ANFIS model.

- Deep learning can solve complex problems that need to find hidden patterns from the available input data. Therefore, advanced artificial intelligence models such as the Long Short-Term Memory (LSTM) model are highly recommended to be used in the future.

- Developing a smart system as an alternative tool to predict the arsenic (or other heavy metal/s) removal from contaminated drinking/ground/irrigation/wastewater is very important to save cost and time. Further investigation in this regard is currently under consideration.

Author Contributions: All authors contributed significantly to the completion of this article, but they had different roles in all aspects. Conceptualization, M.A.-Y.; methodology, M.A.-Y. and T.H.H.A.; software, T.H.H.A.; formal analysis, M.A.-Y. and T.H.H.A.; investigation, M.A.-Y. and T.H.H.A.; data curation, M.A.-Y. and T.H.H.A.; visualization, M.A.-Y. and T.H.H.A.; validation, M.A.-Y. and S.R.; project administration, M.A.-Y.; funding acquisition, M.A.-Y.; writing—original draft, M.A.-Y., T.H.H.A. and S.R.; writing-review and editing, M.A.-Y., T.H.H.A. and S.R. All authors have read and agreed to the published version of the manuscript.

Funding: This research and the APC were funded by the Deanship of Scientific Research at King Faisal University (Saudi Arabia), Annual Research Program (Grant No. 160152).

Institutional Review Board Statement: Not applicable.

Informed Consent Statement: Not applicable.

Acknowledgments: The authors gratefully thank the Deanship of Scientific Research at King Faisal University (Saudi Arabia) for the financial support under the Annual Research Program (Grant No. 160152).

Conflicts of Interest: The authors declare no conflict of interest.

\section{References}

1. Ravenscroft, P.; Brammer, H.; Richards, K.S. Arsenic Pollution: A Global Synthesis, 2nd ed.; Wiley-Blackwell: Hoboken, NJ, USA, 2011; pp. 1-21.

2. Shankar, S.; Shanker, U. Arsenic contamination of groundwater: A review of sources, prevalence, health risks, and strategies for mitigation. Sci. World J. 2014, 2014, 304524. [CrossRef] [PubMed]

3. Mólgora, C.; Domínguez, A.; Avila, E.; Drogui, P.; Buelna, G. Removal of arsenic from drinking water: A comparative study between electrocoagulation-microfiltration and chemical coagulation-microfiltration processes. Sep. Purif. Technol. 2013, 118, 645-651. [CrossRef]

4. Pal, P.; Chakrabortty, S.; Linnanen, L. A nanofiltration-coagulation integrated system for separation and stabilization of arsenic from groundwater. Sci. Total Environ. 2014, 476, 601-610. [CrossRef] [PubMed]

5. Glass, S.; Mantel, T.; Appold, M.; Sen, S.; Usman, M.; Ernst, M.; Filiz, V. Amine-terminated PAN membranes as anion-adsorber materials. Chem. Ing. Tech. 2021, 93, 1396-1400. [CrossRef] 
6. $\quad$ Nicomel, N.R.; Leus, K.; Folens, K.; Van Der Voort, P.; Du Laing, G. Technologies for arsenic removal from water: Current status and future perspectives. Int. J. Environ. Res. 2016, 13, 62. [CrossRef]

7. Aremu, J.; Rozi, H.; Lay, M.; Glasgow, G.; Ahuja, G. Arsenic Removal from Drinking Water Using Silica Based Catalytic Media. In Proceedings of the Water New Zealand Conference and Expo. Conference, Hamilton, New Zealand, 20-22 September 2017; Available online: https:/ / www.waternz.org.nz/Article?Action=View\&Article_id=1383 (accessed on 20 December 2021).

8. Rybka, K.; Matusik, J.; Slaný, M. Technical aspects of selected minerals transformation to LDH-containing materials: The structure, chemistry and affinity towards As(V). J. Environ. Chem. Eng. 2021, 9, 106792. [CrossRef]

9. Usman, M.; Zarebanadkouki, M.; Waseem, M.; Katsoyiannis, I.A.; Ernst, M. Mathematical modeling of arsenic(V) adsorption onto iron oxyhydroxides in an adsorption-submerged membrane hybrid system. J. Hazard. Mater. 2020, 400, 123221. [CrossRef] [PubMed]

10. Usman, M.; Belkasmi, A.I.; Kastoyiannis, I.A.; Ernst, M. Pre-deposited dynamic membrane adsorber formed of microscale conventional iron oxide-based adsorbents to remove arsenic from water: Application study and mathematical modeling. J. Chem. Technol. Biotechnol. 2021, 96, 1504-1514. [CrossRef]

11. Akin, I.; Arslan, G.; Tor, A.; Ersoz, M.; Cengeloglu, Y. Arsenic (V) removal from underground water by magnetic nanoparticles synthesized from waste red mud. J. Hazard. Mater. 2012, 235, 62-68. [CrossRef] [PubMed]

12. Mandal, S.; Sahu, M.; Patel, R. Adsorption studies of arsenic (III) removal from water by zirconium polyacrylamide hybrid material (ZrPACM-43). Water Resour. Ind. 2013, 4, 51-67. [CrossRef]

13. Ansari, R.; Sadegh, M. Application of activated carbon for removal of arsenic ions from aqueous solutions. Electron. J. Chem. 2007, 4, 103-108. [CrossRef]

14. Yadav, K.; Raphi, M.; Jagadevan, S. Adsorption of copper (II) on chemically modified biochar: A single-stage batch adsorber design and predictive modeling through artificial neural network. Biomass Convers. Biorefin. 2021, 1-16. [CrossRef]

15. Mandal, S.; Mahapatra, S.; Sahu, M.; Patel, R. Artificial neural network modelling of As (III) removal from water by novel hybrid material. Process Saf. Environ. Prot. 2015, 93, 249-264. [CrossRef]

16. Podder, M.S.; Majumder, C.B. The use of artificial neural network for modelling of phycoremediation of toxic elements As(III) and $\mathrm{As}(\mathrm{V})$ from wastewater using Botryococcus braunii. Spectrochim. Acta A Mol. Biomol. Spectrosc. 2016, 155, 130-145. [CrossRef] [PubMed]

17. Podder, M.S.; Majumder, C.B. Prediction of phycoremediation of As (III) and As (V) from synthetic wastewater by Chlorella pyrenoidosa using artificial neural network. Appl. Water Sci. 2017, 7, 3949-3971. [CrossRef]

18. Singh, D.; Verma, D.; Singh, Y.; Hasan, S. Preparation of CuO nanoparticles using Tamarindus indica pulp extract for removal of As (III): Optimization of adsorption process by ANN-GA. J. Environ. Chem. Eng. 2017, 5, 1302-1318. [CrossRef]

19. Zhu, X.; Wang, X.; Ok, Y.S. The application of machine learning methods for prediction of metal sorption onto biochars. J. Hazard. Mater. 2019, 378, 120727. [CrossRef] [PubMed]

20. Hafsa, N.; Rushd, S.; Al-Yaari, M.; Rahman, M. A Generalized Method for Modeling the Adsorption of Heavy Metals with Machine Learning Algorithms. Water 2020, 12, 3490. [CrossRef]

21. Hafsa, N.; Al-Yaari, M.; Rushd, S. Prediction of arsenic removal in aqueous solutions with non-neural network algorithms. Can. J. Chem. Eng. 2021, 99, S135-S146. [CrossRef]

22. Bhagat, S.K.; Pyrgaki, K.; Salih, S.Q.; Tiyasha, T.; Beyaztas, U.; Shahid, S.; Yaseen, Z.M. Prediction of copper ions adsorption by attapulgite adsorbent using tuned-artificial intelligence model. Chemosphere 2021, 276, 130162. [CrossRef]

23. El Hanandeh, A.; Mahdi, Z.; Imtiaz, M.S. Modelling of the adsorption of $\mathrm{Pb}, \mathrm{Cu}$ and Ni ions from single and multi-component aqueous solutions by date seed derived biochar: Comparison of six machine learning approaches. Environ. Res. 2021, $192,110338$. [CrossRef] [PubMed]

24. Ke, B.; Nguyen, H.; Bui, X.N.; Bui, H.B.; Nguyen-Thoi, T. Prediction of the sorption efficiency of heavy metal onto biochar using a robust combination of fuzzy C-means clustering and back-propagation neural network. J. Environ. Manag. 2021, $293,112808$. [CrossRef]

25. Foroutan, R.; Peighambardoust, S.J.; Mohammadi, R.; Omidvar, M.; Sorial, G.A.; Ramavandi, B. Influence of chitosan and magnetic iron nanoparticles on chromium adsorption behavior of natural clay: Adaptive neuro-fuzzy inference modeling. Int. J. Biol. Macromol. 2020, 151, 355-365. [CrossRef] [PubMed]

26. Dolatabadi, M.; Mehrabpour, M.; Esfandyari, M.; Alidadi, H.; Davoudi, M. Modeling of simultaneous adsorption of dye and metal ion by sawdust from aqueous solution using of ANN and ANFIS. Chemometr. Intell. Lab. Syst. 2018, 181, 72-78. [CrossRef]

27. Wong, Y.J.; Arumugasamy, S.K.; Chung, C.H.; Selvarajoo, A.; Sethu, V. Comparative study of artificial neural network (ANN), adaptive neuro-fuzzy inference system (ANFIS) and multiple linear regression (MLR) for modeling of Cu (II) adsorption from aqueous solution using biochar derived from rambutan (Nephelium lappaceum) peel. Environ. Monit. Assess. 2020, $192,439$. [CrossRef]

28. Alam, G.; Ihsanullah, I.; Naushad, M.; Sillanpää, M. Applications of artificial intelligence in water treatment for optimization and automation of adsorption processes: Recent advances and prospects. Chem. Eng. J. 2022, 427, 130011. [CrossRef]

29. Taoufik, N.; Boumya, W.; Achak, M.; Chennouk, H.; Dewil, R.; Barka, N. The state of art on the prediction of efficiency and modeling of the processes of pollutants removal based on machine learning. Sci. Total Environ. 2022, 807, 150554. [CrossRef] [PubMed] 
30. Rahman, M.; Samad, A.; Alam, A. Removal of arsenic with oyster shell: Experimental measurements. Pak. J. Anal. Environ. Chem. 2008, 9, 69-77.

31. Giri, A.; Patel, R.; Mahapatra, S. Artificial neural network (ANN) approach for modelling of arsenic (III) biosorption from aqueous solution by living cells of Bacillus cereus biomass. Chem. Eng. J. 2011, 178, 15-25. [CrossRef]

32. Kamsonlian, S.; Suresh, S.; Majumder, C.B.; Chand, S. Biosorption of as (III) from contaminated water onto low cost palm bark biomass. Int. J. Curr. Eng. Technol. 2012, 2, 153-158. Available online: https://inpressco.com/wp-content/uploads / 2012/03/ Paper3153-158.pdf (accessed on 20 December 2021).

33. Jang, J. ANFIS: Adaptive-network-based fuzzy inference system. IEEE Trans. Syst. Man Cybern. 1993, 23, 665-685. [CrossRef]

34. Nguyen, P.T.; Tuyen, T.T.; Shirzadi, A.; Pham, B.T.; Shahabi, H.; Omidvar, E.; Amini, A.; Entezami, H.; Prakash, I.; Phong, T.V. Development of a Novel Hybrid Intelligence Approach for Landslide Spatial Prediction. Appl. Sci. 2019, 9, 2824. [CrossRef]

35. Kaloop, M.R.; Kumar, D.; Samui, P.; Gabr, A.R.; Hu, J.W.; Jin, X.; Roy, B. Particle Swarm Optimization Algorithm-Extreme Learning Machine (PSO-ELM) Model for Predicting Resilient Modulus of Stabilized Aggregate Bases. Appl. Sci. 2019,9 , 3221. [CrossRef]

36. Xu, H.; Zhou, J.; Asteris, P.G.; Armaghani, D.J.; Tahir, M.M. Supervised Machine Learning Techniques to the Prediction of Tunnel Boring Machine Penetration Rate. Appl. Sci. 2019, 9, 3715. [CrossRef]

37. Le, L.T.; Nguyen, H.; Dou, J.; Zhou, J. A Comparative Study of PSO-ANN, GA-ANN, ICA-ANN, and ABC-ANN in Estimating the Heating Load of Buildings' Energy Efficiency for Smart City Planning. Appl. Sci. 2019, 9, 2630. [CrossRef]

38. Pham, B.T.; Son, L.H.; Hoang, T.-A.; Nguyen, D.-M.; Bui, D.T. Prediction of shear strength of soft soil using machine learning methods. Catena 2018, 166, 181-191. [CrossRef]

39. Sen, S.; Sezer, E.A.; Gokceoglu, C.; Yagiz, S. On sampling strategies for small and continuous data with the modeling of genetic programming and adaptive neuro-fuzzy inference system. J. Intell. Fuzzy Syst. 2012, 23, 297-304. [CrossRef]

40. Jang, J.; Sun, C.; Mizutani, E. Neuro-Fuzzy and Soft Computing-A Computational Approach to Learning and Machine Intelligence. IEEE Trans. Autom. Control. 1997, 42, 1482-1484. [CrossRef]

41. Esmaeili, M.; Osanloo, M.; Rashidinejad, F.; Aghajani Bazzazi, A.; Taji, M. Multiple regressions, ANN and ANFIS models for prediction of backbreak in the open pit blasting. Eng. Comput. 2014, 30, 549-558. [CrossRef]

42. Pham, B.T.; Nguyen, M.D.; Van Dao, D.; Prakash, I.; Ly, H.B.; Le, T.T.; Ho, L.S.; Nguyen, K.T.; Ngo, T.Q.; Hoang, V.; et al. Development of artificial intelligence models for the prediction of Compression Coefficient of soil: An application of Monte Carlo sensitivity analysis. Sci. Total Environ. 2019, 679, 172-184. [CrossRef]

43. Pham, B.T.; Jaafari, A.; Prakash, I.; Singh, S.K.; Quoc, N.K.; Bui, D.T. Hybrid computational intelligence models for groundwater potential mapping. Catena 2019, 182, 104101. [CrossRef]

44. Abraham, A. Adaptation of Fuzzy Inference System Using Neural Learning. In Granular Computing; Springer Science and Business Media, LLC: Berlin, Germany, 2005; Volume 181, pp. 53-83. [CrossRef]

45. Nguyen, H.-L.; Le, T.-H.; Pham, C.-T.; Le, T.-T.; Ho, L.S.; Le, V.M.; Pham, B.T.; Ly, H.-B. Development of Hybrid Artificial Intelligence Approaches and a Support Vector Machine Algorithm for Predicting the Marshall Parameters of Stone Matrix Asphalt. Appl. Sci. 2019, 9, 3172. [CrossRef]

46. Al-Yaari, M.; Saleh, T.A.; Saber, O. Removal of mercury from polluted water by a novel composite of polymer carbon nanofiber: Kinetic, isotherm, and thermodynamic studies. RSC Adv. 2021, 11, 380-389. [CrossRef] 